UNIO - EU Law Journal. Vol. 7, No. 1, July 2021, pp 67-81.

®2021 Centre of Studies in European Union Law

School of Law - University of Minho

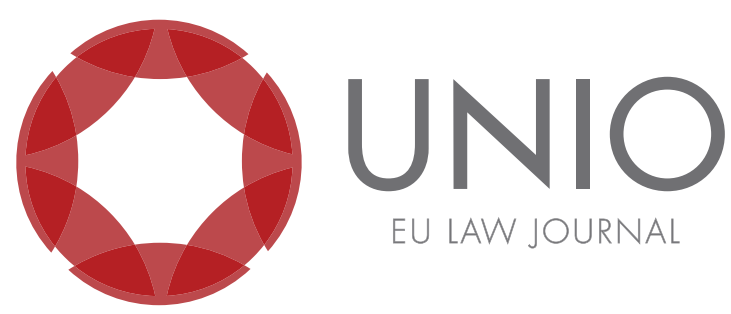

\title{
Instant democracy: a look forward to the EU's digital future
}

\section{Miguel Pereira*}

ABSTRACT: Democracy's resilience is being put to the test by the $21^{\text {st }}$ century. The impact of globalisation and digitalisation has disenfranchised many but so have traditional democratic practices. In an era of constant and immediate communication, with society embracing technological advances while struggling to cope with its inadvertent effects, democracy is still tethered to traditional practices that limit citizens' roles to casting their ballots every few years. However, theory is now being put to the test and experiments with digital democracy are popping up across the globe. In this article, we cover three participative democracy instruments, namely the European Citizens Initiative, e-Voting and e-Participatory Budgeting, delving into theirpotential and identifying their limitations, in the context of the European Union. We also cover the unforeseen threats to democracy posed by information security issues and social media.

KEYWORDS: Digital democracy - e-democracy - social media - information security.

\footnotetext{
* Master's student in European Union Law at the School of Law of the University of Minho.
} 


\section{Introduction}

Turbulence is on the rise across the democratic world. Democracy and its institutions are wounded. Not just bruises, but punctures which keep festering, easily spreading the disease. There are many reasons that we could adduce to justify its state and most of them essentially boil down to the increased effects of globalisation and the disillusionment of citizens with democratic life.

Globalisation, which has widened the rift between fellow countryman, that has pitted the "bigot redneck" against the "out-of-touch liberal elites", the country folk against the city dwellers, the working men and women against the "subsidired parasites". ${ }^{1}$ The disillusionment with democratic life, resulting from years of stagnant economic growth for the low and middle class, corruption scandals involving the highest political offices, the feeling that basic wants and needs go unheard by elected officials and the polarization of political discourse, push a great many to the extremes of the political spectrum where the deceivingly warm embrace of avid agitators awaits.

One can only conclude that we were taken by surprise (even though the telltale signs were there). Yasha Mounk notes how "liberal democracy" was declared triumphant in the late 1980's, how we thought it was so deeply rooted in the world's democratic bastions that we rested, assured that the future would not be too different or more unstable than the present was... Then, the future arrived, and it was not what we expected. $^{2}$

Three paragraphs are enough to paint a very bleak picture. The rest of this paper will change focus and try to shed some light on the way forward, towards a more promising future. We intend to show how the European Union ("EU") can answer some of the issues we have highlighted, what it has done so far and what we view as the best starting point for the reinforcement of the democratic values that lay at the core of the EU. We will do so by reference to the main initiatives that have been designed in the context of digital democracy, ${ }^{3}$ providing an overview of the measures that have so far been implemented and their results, discussing additional possibilities and detailing the potential barriers or threats to their implementation and to online democratic life.

The EU gathers essential elements that make it a prime candidate to experiment with new ways of looking at and experiencing democracy. From its inception, it has been an experiment in a new way for society to organise itself, for public power to be structured and for nations to come together in the pursuit of common objectives. In this context, equating new methods to reinvent democracy and reconfigure the way public powers direct their efforts to meet the needs of citizens is not only desirable but could be vital for the prospering and survival of the European project.

The EU can be perceived as a form of deterritorialisation (of power), based on how the EU's institutions exercise their powers within the confines of a fluid attribution of competences, conceded by and shared with its Member States. This exercise of power often brings it closer to its citizens and often draws it back

\footnotetext{
${ }^{1}$ Paul Collier, O Futuro do capitalismo - enfrentar as novas ansiedades (Alfragide: Dom Quixote, 2019), 13-19.

${ }^{2}$ Yascha Mounk, Povo vs. Democracia (Alfragide: Lua de Papel, 2019), 7-26.

${ }^{3}$ We will mainly refer to the expression "digital democracy" as opposed to "electronic democracy" or "e-democracy", used by a sizeable portion of the literature in the matter, as we believe it translates more clearly the connection between these processes and the internet-based tools that given them form. At certain points we will make reference to some of the solutions with the prefix " $e$ " for ease of reference regarding the cited literature or to better distinguish the online methods from the offline ones.
} 
from them, to give room for Member States to fulfil their attributions. Noting how deterritorialisation is a defining feature of the current globalisation dynamics, Alessandra Silveira and Pedro Madeira Froufe highlight the fact that we seem to be reaching a new frontier in the organisation of public powers, which will necessarily require that we rethink the way we "think, act and interact" with public powers, even more so considering the rise of digital tools which provide for instant and global communication. ${ }^{4}$ In this context, they see, much to our agreeance, that the fluidity and malleability of the partitioning of powers and competences that is characteristic of the EU's institutions (between themselves and in relation to the Member States) is more adequate to answer the challenges that globalisation has brought about. ${ }^{5}$

This new frontier will certainly have to reflect innovative versions of democratic interaction. We would argue that that evolution has already started, that it is ongoing. We have witnessed it, from its earliest forms, envisaged as direct democracy, evolving to representative democracy - as an answer to the increasing complexity of society and the relations that are established in its midst -, to the emergence of participatory democracy, as a complement to representativeness, seeking to engage citizens in the decision-making processes which tend to affect them more directly. ${ }^{6}$ This seems to be the trend of evolution in the field and is the corner stone of the methods we will review.

As a final note, we would like to highlight the internet's potential to be the medium by which democracy might realize this latest stage of its evolution. To that effect, we borrow Dipayan Ghosh's words: “the internet - and, more basically, connectivity - will persistently find ways to break. inefficient and ineffective institutions; it is in the internet's nature to tear down artificially imposed barriers by reaping the benefits of its low transaction costs and minimised friction, challenging aging methods, industries, governmental regimes, and political systems in the process".

\section{Digital democracy instruments}

Having established how the EU is best placed to experiment with new forms of democracy, and how the internet can be a driving force behind the efforts to give shape to participative democracy, we will now dive into the more technical aspects of the discussion.

Definitions of digital democracy vary greatly in literature and are intrinsically connected to the view of democracy and decision-making processes espoused by any given political system. The dominant view focuses on conceptions of participatory and deliberative democracy (here understood as those systems that privilege the creation of spaces for rational and fair public deliberation of issues). ${ }^{8}$ From these

\footnotetext{
${ }^{4}$ Alessandra Silveira and Pedro Madeira Froufe, "A teoria da organização jurídica dos sistemas federativos e o desafio da desterritorialização do poder: qual o papel da experiência federativa europeia?", in Federalismo em tempos de renacionalização (Coimbra: Almedina, 2019), 167-190.

${ }^{5}$ Alessandra Silveira and Pedro Madeira Froufe, "A teoria da organização jurídica dos sistemas federativos", 187.

${ }^{6}$ Alessandra Silveira, Princípios de direito da União Europeia. Doutrina e jurisprudência (Lisbon: Quid Iuris, 2011), 51-52.

${ }^{7}$ Dipayan Gosh, Terms of disservice: how Silicon Valley is destructive by design (Washington: Brookings Institution Press, 2020), ebook edition.

${ }^{8}$ Ralph Linder and Georg Aichholzer, "e-Democracy: conceptual foundations and recent trends", in European e-Democracy in practice, eds. Leonhard Hennen et al. (Cham: Springer, 2020), https://doi. org/10.1007/978-3-030-27184-8.
} 
different perspectives, results caused divergent views on the contributions that digital tools can have in the context of democratic participation, with some reserving special focus to the information potential that digital tools present, while others dedicate special interest to the participatory possibilities in decision-making that the internetbased systems have. ${ }^{9}$

In the next sections we will review three mechanisms, focusing on e-petitioning, e-voting and e-participatory budgeting, selected due to their specific characteristics which allow for greater interaction on the decision-making process as a whole and the legislative process in particular. ${ }^{10}$ For the moment, it suffices to align ourselves with one of the simplest and broader definitions of digital democracy that Ralf Linder and Georg Aichholzer identify in their review: "Digital democracy can be defined as the pursuit and the practice of democracy in whatever view using digital media in online and offline political communication". ${ }^{11}$

\subsection{E-petitioning: the European Citizens Initiative}

The Treaty on European Union ("TEU"), in its Preamble, sets out the objective of "creating an ever closer union among the peoples of Europe, in which decisions are taken as closely as possible to the citizen". This purpose is one of the defining distinctive features that make the EU more than an international organisation focusing on mere regional cooperation. It is in looking to fulfil this objective that nationals of Member States have witnessed the recognition, in their favor, of social and political rights, which have been condensed to form the EU Citizenship. ${ }^{12}$ With the dawn of the EU Citizenship, the EU institutions were faced with the need to give effect to those political rights, and special focus was given to bridging the gap between the citizens and the EU institutions themselves.

Article 11 TEU lays out the obligations impending on the EU institutions in this regard, whereby the EU institutions will give an opportunity to citizens and their representative associations to make their views publicly known, allow for the open exchange of those positions, and maintain an "open, transparent and regular dialogue" with their representative associations and civil society.

As regards the European Commission ("Commission"), the obligations impeding on this institution are more specific. The Commission is obliged to conduct "broad consultations with the parties concerned" and, more relevantly to the present study, upon the initiative of at least one million citizens of a significant number of Member States, submit a proposal for the adoption of a legal act for the purpose of attaining an objective of the Treaties.

\footnotetext{
${ }^{9}$ Ralph Linder and Georg Aichholzer, "e-Democracy: conceptual foundations and recent trends", 12-23.

${ }^{10}$ We will not cover the issue of consultations in this paper. While their impact on the legislative process is quite considerable, the subject matter of these consultation tends to be so specialized and technical in nature that inputs from the "common" citizen are infrequent. Another topic that will fall outside our scope, this one for restrictions of space, is the Petitioning of the European Parliament, a subject to which we will make only brief reference.

${ }^{11}$ Jan van Dijk, "Digital democracy: vision and reality", in Public Administration in the information age: revisited (Amsterdam: IOS-Press, 2012) seen in Leonard Hennen et al., European e-Democracy in practice, 16.

${ }^{12}$ Providing a view on the evolution, the concept of EU citizenship and the implications of its recognition, see Alessandra Silveira, "Cidadania europeia e direitos fundamentais", in Direito da União Europeia - elementos de direito e politicas da União (Coimbra: Almedina, 2016), 17-72.
} 
The European Citizens Initiative ("ECI") is the result of the formalisation of the procedure - as was required by Article 24 of the Treaty on the Functioning of the European Union ("TFEU") - which translated first in the adoption of Regulation $211 / 2011$, then updated, repealed and replaced by Regulation $2019 / 788 .{ }^{13}$ It is the first initiative of its kind, being hailed as the first supranational citizens' initiative ${ }^{14}$ and, in fact, the first transnational instrument of participatory democracy. ${ }^{15}$

As the right of legislative initiative lies with the Commission (thought the European Parliament and the Council of the European Union might request the proposition of specific legislation ${ }^{16}$ ) the ECI is essentially a mechanism at the disposal of the EU citizens to entice the Commission to act in the pursuit of a Treaty objective, with a view to enact legislation. The ECI requires that a group of organizers consisting of at least 7 EU citizens, residing in at least 7 different Member States, of age to be entitled to vote in elections for the European Parliament, register an initiative with the Commission. The Commission is entitled to refuse the registration of an initiative if: 1) it does not fulfil the technical requirements set out in Article 6 (3) (a) and (b) Regulation 2019/788; 2) the initiative (or parts of it) falls outside the scope of the Commission's powers to submit a proposal for a legal act of the Union with the purpose of implementing the Treaties; 3) the initiative is manifestly abusive, frivolous or vexatious; or, 4) the initiative is manifestly contrary to the values of the Union (as set out in Article 2 TEU and the Charter of Fundamental Rights of the European Union). Upon confirmation of these requirements, the initiative is registered and made public. In the cases in which the parts of the initiative fall outside the scope of the Commissions powers, as outlined in Article 6 (3) (c) Regulation 2019/788, and after an invitation by the Commission to amend it, the organisers might choose to maintain its full content, in which case the Commission might decide to partially register the initiative.

For an initiative to be successful it needs to gather at least 1 million signatures from EU citizens, from at least one quarter of the Member States and meeting the minimum number of signatures per country as defined in Annex I of the Regulation. The collection of signatures last for 12 months and starts on the date specified by the organisers, which should, nevertheless, be within 6 months of the registration of the ECI. The signatures, known as statements of support, may be collected in paper format or through online collection systems. As of 2020, the Commission has set up one such system that the organisers may use free of charge, in which supporters may register the statements by means of notified electronic identification. Alternatively, the organisers may use other collection systems. When they opt for that system, the organisers must upload the paper signatures to the central online collection system hosted by the Commission. Member States must validate the signatures (both paper and online) within the 3 months following the submission by the organisers to the competent authorities of each of the Member States in which signatures were collected.

\footnotetext{
${ }^{13}$ Regulation 2019/788 of the European Parliament and of the Council of 17 April 2019 on the European citizens' initiative.

${ }^{14}$ Maximilian Conrad, 'The European citizens' initiative: transnational democracy in the EU at last?", Icelandic Review of Politics \& Administration, v. 7, no. 1 (2011): 5-22, http://www.irpa.is/article/ view/a.2011.7.1.1/pdf_206.

15 Georg Aichholzer and Gloria Rose, "Experience with digital tools in different types of e-Participation", in European e-Democracy in practice, 120.

${ }^{16}$ Tiago Sérgio Cabral, "A short guide to the legislative procedure in the European Union”, UNIO EU Law Journal, v. 6, no. 1, (2020): 161-180.
} 
At this stage, if the required number of validated statements has been reached, the Commission will notify it to the Council, the European Economic and Social Committee, the Committee of the Regions, the national Parliaments, and the European Parliament, which will host a public hearing in which the organisers may present the initiative. This is followed by a meeting with the Commission in which the organisers get a chance to provide additional details on the initiative. Within 6 months of the public hearing held at the European Parliament, the Commission shall inform the organisers of whether it intends to pursue any action and the timelines for said action in the affirmative, providing a reason for the refusal to take action.

From the above description, it is easy to note how difficult it might be to see an initiative reach the required number of signatures, much less to reach the stage where the Commission decides on whether it will act or not. This difficulty has been noted in many studies, and the most frequent conclusion is that the apparatus required to engage in an ECI is usually restricted to civil society organisations, which, due to their established structures, can reach a wider European audience. ${ }^{17}$ While digital tools facilitate this exercise to some extent (two thirds of the petitions use online collection systems), ${ }^{18}$ aiding not only with the collection process, but also with the associated campaigning, it does not seem that they go a long way in making it an accessible means to a group of "average" citizens. This is further compounded by the heavy costs of setting up the campaigning operation which, to be successful, demands that organisers make their platforms available in as many languages as possible (this is, in fact, a recurring issue in the context of implementing digital democracy tools in the EU).

While the ECI seems to have contributed to a reinforcement of civil society organisations, allowing for greater access to the EU Institutions for those that are not based in Brussels, ${ }^{19}$ it seems it might have fallen short of the expectations that surrounded it, having only a marginal effect on the involvement of the average EU citizen.

\subsection{E-voting: how suitable for the EU?}

E-voting is the more direct form of participatory digital democracy that has so far been experimented. None of these experiments were conducted at EU level and, as it stands, only one Member State (Estonia) has definitively implemented this form of suffrage. Estonia is singled out in almost every piece of recent literature in the context of online voting, having made this modality available in all the elections (local, national and for the European Parliament), with 31\% of the total number of votes being casted online in the 2015 elections. ${ }^{20}$

The Estonian success with online voting must be read considering the country's specific context. Following the fall of the Soviet Union, the Estonian Government started a great push towards digitalisation, a series of government programs that resulted in the availability of computers with internet access in all schools and

\footnotetext{
17 Georg Aichholzer and Gloria Rose, "Experience with digital tools in different types of e-Participation", 120.

18 Georg Aichholzer and Gloria Rose, "Experience with digital tools in different types of e-Participation", 122.

19 Georg Aichholzer and Gloria Rose, "Experience with digital tools in different types of e-Participation", 120.

${ }^{20}$ Aleksandr Lust, "I-Vote, therefore I am? Internet voting in Switzerland and Estonia", SAIS Review of International Affairs, v. 38, no. 1 (2018): 65-79, https://doi.org/10.1353/sais.2018.0006.
} 
partnerships with private entities having free access to wireless internet in all public spaces. This was coupled with an immense investment in e-government solutions, resulting in many services being accessible online via a digital ID card. As a result, $79 \%$ of Estonians are frequent internet users. ${ }^{21}$

Another example that is usually coupled with Estonia is that of Switzerland which, since the mid-2000s, experimented with online voting in 3 cantons (Geneva, Neuchatel and Zurich) for cantonal and federal referenda. Switzerland has seen a lot of back and forth in this area. Initially only allowing for referenda to be voted on, this was expanded to cover also federal elections in the first 2 cantons, while 12 other cantons had that possibility made available only to Swiss nationals living abroad. As for Zurich, a moratorium was imposed on online voting in $2011 .{ }^{22}$

The debate around the issue in Switzerland has been intense and recently resulted in the withdrawal of the 2 e-voting systems that were available in the country (one hosted by the Geneva canton and another by Swiss Post), mostly for security concerns. ${ }^{23}$ Notwithstanding that, the comparison undertaken by Lust of the results in these 2 countries still allows us to gather some insights. Noting the strong democratic tradition of the country (the average Swiss is called to the ballot box 6/7 times a year to vote on elections or referenda), Lust goes on to highlight how the country has long struggled with low voter turnout (this is in part connected to the late extension of suffrage to women - extension entered into force in 1970s - which seems to have resulted in low numbers of women votes). To invert this trend the government introduced postal voting in the 1980s to which many Swiss adhered to and remains the most used modality ( $80 \%$ of Swiss voters vote by mail). The initiative resulted in a $5 \%$ increase in turnout. Spectators had high hopes for the introduction of e-voting, expecting a similar boom in voter turnout, especially amongst the younger electors. The hope, however, did not translate into reality, with voter turnout stagnating at the same level as previous elections and e-voting effects being negligible ${ }^{24}$ and resulted in no sustained increase in young voter turnout. ${ }^{25}$

A final note regarding this study is the impact on demographics and political bias. A common assertion is that the public which will flock to e-voting is predominantly male, rich and with higher education. ${ }^{26}$ Lust noted that, while this seems to be true in the years ensuing the introduction of e-voting, this trend tends to change, with demographics losing importance but being, however, replaced by two other biases: internet/computer skills and trust in the online voting.

As regards political bias, Lust noted that in Switzerland, given the overall support of the political system and the reduced impact of demographic differences overtime, there was no bias towards voting in one party/political family. The same could not be said about Estonia where a major mistrust by ethnic Russians regarding e-voting (the relation between ethnic Russians and ethnic Estonians as long since been frayed, the mistrust regarding the e-voting system was compounded by the fact that the

\footnotetext{
${ }^{21}$ Aleksander Lust, "I-Vote, therefore I am?", 71.

22 Aleksander Lust, "I-Vote, therefore I am?”, 69.

${ }^{23}$ See Federal Chancellery website, accessed 31 January 2021, https://www.bk.admin.ch/bk/en/ home/politische-rechte/e-voting.html.

${ }^{24}$ Aleksander Lust, "I-Vote, therefore I am?”, 69-71.

25 Georg Aichholzer and Gloria Rose, "Experience with digital tools in different types of e-Participation", 111.

${ }^{26}$ Georg Aichholzer and Gloria Rose, "Experience with digital tools in different types of e-Participation", 111.
} 
early versions of the systems provided only for Estonian language settings), resulted in some parties, usual recipients of the votes of this slice of Estonian society, being underrepresented in online voting.

A central argument in support of e-voting is that it contributes to increased turnout (the other two most adduced arguments are decreased cost with elections and reduced mistakes in tallying the votes). This argument, however, finds limited sustenance in empirical evidence, as we have seen. Considering the pilot projects carried out in several EU Member States, no increase in turnout was detected (though interest in the particular elections is a fact to be considered in reviewing the results, not just the method by which voters cast their ballots). ${ }^{27}$ If there is anything to learn from the Estonian experience, it is that digital literacy and trust in e-government solutions seem to have an impact on the successful implementation of online voting, though special attention must be paid to representation in order to avoid a divide on the participation of different electorates that might lead to questioning the legitimacy of the results.

So far, we have highlighted the importance of trust in computer systems if e-voting is to be successfully incorporated into the electoral system of a given country. The literature has noted that, while some countries enjoy high levels of trust in e-voting, this has not quashed objections based on security issues - this resulted in the halting of e-voting in Switzerland until upgrades to the available online voting systems are made. We will have an opportunity to delve into the security issues in the last section but for now, we will focus on the judicial complaints that they have given rise to. In both Switzerland and Estonia, judicial cases were lodged alleging potential security breaches in the underlying systems supporting e-voting. In both cases, the complaints were dismissed by the national courts on the grounds that actual breaches had to be proven for results to be invalidated, with the courts declining to perform an overall assessment of systems and their compatibility with electoral laws. ${ }^{28}$ The same was not the case in Germany and in Austria, where the Constitutional Courts considered that one of the fundamental elements of the electoral system is the electorate's ability to adequately verify the validity of their vote without the need to have specialised knowledge - this applies to the electoral commission, in the Austrian case, with the Constitutional Court considering that the electoral commission should be able to perform their duty without outside technical help. ${ }^{29}$

Aleksandr Lust insightfully remarks that, regarding the EU, the conditions governing the ability and willingness of citizens to use the internet and digital tools vary wieldy across the Member States, which would give rise to a very heterogenous use of the tool in the continent. The author also expresses his concern, about the ethnic division that became apparent in Estonia and the negative effect that e-voting could have on those European societies which deal with considerable socioeconomic, ethnic and religious divisions (exemplifying with Latvia, Bulgaria, Romania, and Croatia), which could be deepened by the implementation of online voting, as was the case in Estonia.

\footnotetext{
${ }^{27}$ Aleksander Lust, "I-Vote, therefore I am?", 66.

${ }^{28}$ Georg Aichholzer and Gloria Rose, "Experience with digital tools in different types of e-Participation", 110.

${ }^{29}$ Ardita Driza Maurer and Jordi Barrat, eds., e-Voting case law: a comparative analysis (New York: Routledge, 2016), 3, https://books.google.pt/books?hl=pt-PT\&lr=lang_en\%7Clang_it\%7Clang_pt \&id=MLC1CwAAQBAJ\&oi=fnd\&pg=PA1\&dq= switzerland + cancels + e-voting\&ots $=$ suRfX$33 \mathrm{qN} \& \operatorname{sig}=\mathrm{LNq} 3 \mathrm{hdUKz} 3 \mathrm{knYC6d} 7 \mathrm{v} 4 \mathrm{QxdQk} 2 \mathrm{~h} 4 \&$ redir_esc $=\mathrm{y} \# \mathrm{v}=$ onepage $\& \mathrm{q}=$ switzerland $\% 20$ cancels $\% 20 \mathrm{e}$-voting $\& \mathrm{f}=$ false.
} 
Georg Aichholzer and Gloria Rose seem to echo some of these concerns, stating that the EU should focus on improving the existing methods, experimenting with new forms of participatory democracy that depart from the more State-centered models and to focus on building the European Parliament and its parliamentarians as bridges to the EU and conduits for the general population to have an impact on policy making. ${ }^{30}$

\subsection{E-participatory budgeting: a way forward?}

Participatory budgeting has been around since 1989, when it was introduced in Porto Alegre, Brazil, and it allows for citizens to take part in the decisions regarding the budgeting of fractions of the municipal budget. E-participatory budgeting is the latest stage of its development, allowing for the citizens' contributions to be provided through digital media tools.

Participatory budgeting may take different forms, with some being actual decision-making processes, others having a non-binding, consultive, nature which contributes to shaping the final decision taken by the representatives in charge of preparing the budget. ${ }^{31}$ This instrument has been adopted throughout the world with many municipalities in Europe implementing it and making 1-20\% of the municipal budget available for this purpose. Georg Aichholzer and Gloria Rose synthesised the impacts that participatory budgeting has garnered in Europe, highlighted in the relevant literature, as follows: "support for the demand for increased transparency, improved public services, accelerated administrative operations, better cooperation amongstpublic administration units and enhanced responsiveness. Positive contributions to the political culture and competences of participants can also be expected. This can include extended participation opportunities, enhanced transparency of publicpolicy, better quality of decision-making, increased legitimacy and a stronger identification with the local community. Cost reduction and major structural reforms are less likely achieved." 32

The general note in the studies that were reviewed by these authors is incredibly positive, with impacts being measurable in increased quality of public services and increased trust in local government, though always through a combination of online and offline participation to achieve optimal results. The authors also noted a lack of integration with social media, whose engagement is perceived to be a potentially positive contribution to e-participatory budgeting. There have also been some successful cases of implementation of gamification in e-participatory budgeting (though, in some cases, some less positive outcomes have also been detected, such as distancing from other political channels such as public protest and campaigning). ${ }^{33}$ In general, we believe that enticing designs and features that promote engagement with the e-participatory budgeting tools are welcome (though not all of the features usually associated with gamifying seem adequate in the context of a digital democracy

\footnotetext{
${ }^{30}$ Georg Aichholzer and Gloria Rose, "Experience with digital tools in different types of e-Participation", 130.

31 Georg Aichholzer and Gloria Rose, "Experience with digital tools in different types of e-Participation", 107.

32 Georg Aichholzer and Gloria Rose, "Experience with digital tools in different types of e-Participation", 108.

${ }^{33}$ John Gastil and Michael Broghammer, "Linking theories of motivation, game mechanics, and public deliberation to design an online system for participatory budgeting", Political Studies, v. 69, no. 1 (2021): 7-25.
} 
instrument, such as "leader scoreboards" identifying the most active participants), ${ }^{34}$ though special care must be taken to prevent or, at least, curb the impact of the potential negative side effects we adduced to above, and to prevent the trivialisation of e-participatory budgeting instruments through pure game formats.

It seems that this type of direct intervention is, so far, the best placed to advance participatory democracy and has certainly benefited from digital tools (cost and time saving). We will explore this possibility in our concluding remarks.

\section{Threats: information security and social media}

We have dedicated the last section to exploring some of the digital democracy instruments that have been put to the test across Europe. While not covering all the uses that digital tools and digital media might have in the context of online democratic practice, we highlighted those that revealed a closer connection to the $\mathrm{EU}$, that benefit more from (or were made possible by) digital tools and whose connection to direct participatory democracy is clearer.

The weaknesses and threats we will explore in this section do not relate exclusively to those instruments that were reviewed (though they are applicable as well). They result from the introduction into our daily lives of digital tools that, while connecting the most remote parts of the world to the unimaginably immense wealth of knowledge that the internet comprises and allowing for an unparalleled leap in the development of societies across the world, represent an increasing danger to the stability and transparency of democratic political systems, much to the contrary of the early expectations that technological development created in our collective consciousness.

\subsection{Information Security}

Thomas Rid and Ben Buchanan ${ }^{35}$ make a very critical appraisal of how the "cyber security" ${ }^{36}$ community failed to identify the ways by which malicious actors might try to undermine democracy, by focusing the discussion on antiquated views on the potential that digital tools present and converging the efforts on targets which present a more literal danger than those that, nowadays, are being exploited (the traditional example would be hacking the power grid to sew chaos). Indeed, while attacks on those classic targets still represent a great threat to the stability of any nation, current events have shown how the tactics that are currently being deployed are much more insidious. The 2016 US election brought the issue of foreign election meddling to the forefront of concerns with democracy, with a US Department of Justice investigation revealing a coordinated disinformation campaign allegedly orchestrated out of Russia, which was coupled with successful hacking of political campaigns, resulting in damaging information being released. ${ }^{37}$ While the question of the actual game changing impact it had on the results might never be known, the

\footnotetext{
${ }^{34}$ John Gastil and Michael Broghammer, "Linking theories of motivation", 8.

${ }^{35}$ Thomas Rid and Ben Buchanan, "Hacking democracy", SAIS Review of International Affairs, v. 38, no. 1 (2018): 3-16, https://doi.org/10.1353/sais.2018.0001.

${ }^{36}$ According to the authors, even the designation cyber security is contentious in the debate, with recent trends adopting the expression "information security", which does seem more adequate.

${ }^{37}$ See, Abigail Abrams, “Here’s what we know so far about Russia’s 2016 meddling”, Time, April 18, 2019, https:/ / time.com/5565991/russia-influence-2016-election/.
} 
uncovering of this operation shows us how fragile democracy can be in the face of a few hackers and "internet trolls" with a mission. ${ }^{38}$

As the two authors note, the real target of digital attacks on democracies are not the networks themselves, but rather the institutions which make use of them - institutions whose functioning is based on trust. These institutions comprise not only political parties, campaigns and public bodies but cover also civil society organisations, which fight for the advancement and protection of human rights..$^{3 / 40}$

The next target is the democratic infrastructure, specifically that connected to the electoral system. The potential risks that were identified were the tampering with digital voter registration records (which could allow, for instance, for a deletion of a portion of the registered voters, an action which, if targeting specific groups, could have a considerable impact on election results) and voting machines (from simple malfunctions to adulteration of the tallying of the votes). ${ }^{41}$ In the context of e-voting, as we had a chance to review, the confidence in the durability of the system is not unshakable, so much so, that Switzerland has decided to discontinue e-voting until sufficient security upgrades are made to the online voting systems (vide supra).

Finally, a more traditional approach is to target intelligence agencies directly with a view not only to steal valuable information and technology, but also to discredit them and create barriers to their functioning. The data leaks that brought the NSA's mass surveillance program to light allowed us to have a better sense of how this agency collected its information, in a way which seems to be at odds with the general public's legitimate expectation of privacy. While we can list the benefits of this disclosure, little attention is dispensed to the nefarious results that it also comprised. The leaks not only attacked the agency's credibility in the eyes of those that it set out to protect, but also made it practically and politically difficult for the agency to keep using this tool. Even if the implementation of safeguards regarding its use were, undeniably, in order, one cannot overlook the defensive potential the tool had, nor the absolutely central role the NSA plays in the collective defense of the NATO Member States, with this agency being the most capable amongst all the western democracies and frequently sharing advanced warnings with the NATO allies regarding terrorist plots and espionage campaigns. ${ }^{42} \mathrm{~A}$ balance must be struck between overarching policing of innocent bystanders and the need for democracies

\footnotetext{
${ }^{38}$ The year was also marked by the Brexit referendum by which a small majority of electors voted to oust the United Kingdom out of the EU. In 2018 a story broke out linking the referendum to yet another campaign, allegedly organized by a private contractor, Cambridge Analytica, based on targeted advertising through the usage of data obtained through a breach of Facebook's user data. A recent report, resulting from a 3-year investigation by the UK's Information Commissioner, however, revealed that the company "was not involved" in the referendum. As no explanation has been provided on how the detailed allegations came to light, and given the contradicting report by the supervisory authority, we will not include it in our review: https://www.bbc.com/news/uk-politics-54457407.

${ }^{39}$ Thomas Rid and Ben Buchanan, "Hacking democracy", 9. They give the example of a member of Human Rights Watch, a prominent figure in the United Arab Emirates, which was target by spyware, enabling the UAE's government to track his moves and activities, eventually leading to his arrest.

${ }^{40}$ As regards civil society organizations, it has been noted that the information security threats that they're exposed to go vastly underreported, in comparison to private entities, see Lennart Maschmeyer, Ronald J. Deibert and Jon R. Lindsay, "A tale of two cybers - how threat reporting by cybersecurity firms systematically underrepresents threats to civil society", Journal of Information Technology \& Politics, v. 18, no. 1 (2021), https:/ / doi.org/10.1080/19331681.2020.1776658.

${ }^{41}$ Thomas Rid and Ben Buchanan, "Hacking democracy", 10-11.

${ }^{42}$ Thomas Rid and Ben Buchanan, "Hacking democracy", 12-13.
} 
to be protected from malicious attacks. Finally, the leaks contained more than just a warning of the NSA's actions, among the throve of documents were the blueprints to the program which have since been adapted to produce the notorious ransomware known as "WannaCry" that in 2017 wreaked havoc across the world, among others ${ }^{43}$.

The information security threats keep evolving, with the recent SolarWinds attack bringing new frailties to light. Unlike the traditional approach of attacking the end user, the intended target, one of the techniques used in this attack targeted the software supply-chain, infecting one of SolarWinds' systems (Orion), and spreading the malicious code through the systems of the company's clients via an inoffensive looking software update, resulting in multiple US Federal Agencies facing an unprecedent security breach. ${ }^{44}$

\subsection{Social media}

We have already broached the hazardous potential that social media has for democratic life, by allowing for disinformation to seep into our social and news feeds. The calls to regulate social media are piling up, and are well founded, ${ }^{45}$ but, as Ronald Deiber notes, for any such regulation to be achieved, a shared understanding of the risks we are looking to mitigate must be reached. ${ }^{46}$

The fact remains that their business model presents a challenge to modern day democracies, a business model that can be included in what Shoshana Zuboff has dubbed "surveillance capitalism". ${ }^{47}$ When a company makes money out of data collection, their main goal is to keep users connected to their tools for as long as they can so that the data collected on each individual user is as granular as possible. Many artifices are deployed to fulfill this goal, from design features (such as the infinite scroll, which keeps users hooked without any effort on their part) to content related functionalities (tailored suggestions). This last one resulting is an effect known as "filter bubble", ${ }^{48}$ leading users to comfortable echo chambers free of any information or discourse with which the user might disagree. This functionality read in conjunction with the low quality of the discourse to be found on social media, mostly based on monologues as opposed to dialogues, excluding any meaningful exchange of positions, does nothing in the way of fostering democratic discourse and mutual understanding. ${ }^{49}$

\footnotetext{
${ }^{43}$ Thomas Rid and Ben Buchanan, "Hacking democracy", 12.

${ }^{44}$ Laura Hautala, "SolarWinds not the only company used to hack targets, tech execs say at hearing", CNET, February 24, 2021, https://www.cnet.com/news/solarwinds-not-the-only-company-usedto-hack-targets-tech-execs-say-at-hearing/.

${ }^{45}$ The recent actions by social media companies, in the wake of the Capitol insurrection following the 2020 US presidential elections, blocking the then sitting President of the US from their platforms raised some concerns as to the legitimacy that a handful of board members of tech-giant have to close off a means of communication between an elected official and his constituency. This feeds into the larger discussion around social media policing and freedom of speech.

${ }^{46}$ Ronald J. Deibert, "The road to digital unfreedom: three painful truths about social media", Journal of Democracy, v. 30, no. 1 (2019), https://doi.org/10.1353/jod.2019.0002.

${ }^{47}$ The author offers several definitions of surveillance capitalism, we translate here the first meaning she attributes to it: "A new economic order which appropriates human experience and uses it covertly as raw material in commercial practices of extraction, forecasting and sales", see Shoshana Zuboff, "A definição", in A era do capitalismo de vigilância: a disputa por um futuro bumano na nova fronteira do poder (Lisbon: Relógio D’Água, 2020).

${ }^{48}$ Ronald J. Deibert, "The road to digital unfreedom”, 32.

${ }^{49}$ Ralph Linder and Georg Aichholzer, "e-Democracy: conceptual foundations and recent trends", 31-32.
} 
Social media companies find themselves frequently in the midst of scandals which expose the threats that their business models have created and yet, have found very few ways to mitigate those threats. The pile of anecdotal examples keeps on getting bigger but a good example of their failure to prevent misinformation and disinformation from spreading can be found in the experiment conducted by a group of researchers that posed as Russian trolls (using elements to connect their online presence to the Internet Research Agency, one of the entities identified behind the 2016 disinformation campaign surrounding the US Presidential election, an entity which is currently under sanctions by the US) and easily managed to buy ads from Google., indicating lacking due diligence measures when it comes to accepting new advertisers. ${ }^{50}$

Their potential to be used to whip up hatred that spills out onto the street has already been proven, with Facebook activity being connected to the violence in the context of the ethnic cleansing of Rohingya Muslims in Myanmar. ${ }^{51}$ The troubling new developments are the use of WhatsApp for disinformation spreading purposes. ${ }^{52}$ Given the app's characteristics, taking any action in this regard will prove difficult.

While it is true that a lot of the issues surrounding the use of social media are not connected to the way they operate (or intend to operate) their business, but rather to their use by agitators and malicious actors, given their increased importance in public life, the mounting concern with the activities that are enabled by these platforms, the real life consequences that they have and their increased globalised presence, it seems like the time has come to start debating the next steps on the regulation of the sector, looking to strike a balance between the need to mitigate these risks, the users' right to freedom of expression and the companies' right to private initiative.

Again, the EU finds itself in a privileged position to spearhead such regulatory efforts. The ability to harmonise legislation across $27 \mathrm{Member}$ States (and to influence the legislation of many other States that wish to do business with the bloc) is not only an advantage but seems like it might be a necessity, when it comes to regulating global tech giants. Reaching international consensus on standards that these companies must adhere to would prove to be more that an agonizingly cumbersome process but rather, an impossible task. The EU's particular functioning allows for most of those hurdles to be side stepped, at least as concerns the territory of its Member States (already a sizable portion of the biggest social media platforms' users and revenue generators). The Commission has recently seized upon this opportunity and put forward proposals for the adoption of two Regulations (the Digital Services Act and the Digital Market Acts) which, among other things, seeks to address some of the issues that we have highlighted in this section. ${ }^{53}$ The proposals have yet to be approved but the legislative process is ongoing and, if approved, both Regulations would take effect across the EU and potentially influence other States to follow suit.

\footnotetext{
${ }^{50}$ Ronald J. Deibert, "The road to digital unfreedom", 33.

${ }^{51}$ Ronald J. Deibert, "The road to digital unfreedom", and Dipayan Gosh, Terms of disservice, Introduction.

${ }^{52}$ Ronald J. Deibert, "The road to digital unfreedom", 33.

${ }^{53}$ European Commission, "Proposal for a regulation of the European Parliament and of the Council on a Single Market for Digital Services (Digital Services Act) and amending Directive 2000/31/ EC", Brussels, 15 December 2020, COM(2020) 825 final and European Commission, "Proposal for a regulation of the European Parliament and of the Council On contestable and fair markets in the digital sector (Digital Markets Act)", 15 December 2020, COM(2020) 842 Final.
} 


\section{Concluding remarks}

The concept of "democratic deficit" is one that has, for a long time, plagued the $\mathrm{EU}$ and the functioning of its institutions. Many saw the rise of digital democracy as a potential answer to that. While we agree that the EU's functioning often lacks a certain, undesirable, degree of transparency (the issue with the lack of transparency of trilogues and the unusual way by which the Commission is nominated are good examples $^{54}$ ), we shared the view of Alessandra Silveira that, when put to the standard tests a democratic institution should pass, the EU does not fail. ${ }^{55}$ In our view, the EU's primary challenge is one of communication. Its struggle to get out the many initiatives it has spearheaded, whose contributions are felt by its citizens but which they cannot link to its rightful source is no doubt its main weakness. Alexis Vhalas aligns with this perspective, questioning the reasons for the EU citizens' freedom to circulate, work, settle and study in the full span of its territory not to be hailed as the great achievement that it is. The same rationale applies to the EU's efforts on the international stage, where, in the last 15 years, it has deployed more civilian and military operations than "any other international organization, far abead of the UN, OSCE and NATO". ${ }^{56}$

In our view, increased recourse to digital democracy tools, which foster participative democracy, contribute not only to the democratic development of our society but will certainly help the EU get its message across more clearly and effectively, allowing its citizens to directly link the EU's initiatives to the changes in their environment.

We believe that the first steps should be taken at the local level, using the aforementioned mechanism of participatory budgeting. While participatory budgeting is, now, focused on funding projects that find their inception in citizen's initiatives, we argue that that their scope could be expanded to cover more traditional areas of autarchic involvement which relate to public utilities. Local assemblies are called upon each year to decide on the amount of funds that are to be granted to local public services, and this often involves deciding on which of these should get the biggest slice of the budget with a view to improve those services or address specific needs that have been identified. This type of debate provides an avenue not only to attract citizens to local decision making (no specific political knowledge is needed and the impact of the decisions is felt directly and more immediately), but also to address the needs that they register in their daily lives. Whom better than those that use the city buses and the city's trash collection system to decide on whether they need improvement or not? The funding for these services cannot, naturally, be entirely dependent on public voting (nor should this be done exclusively online, a combination of online and offline methods would maximize results, as we've seen above) as the externalities related to voter representation we have addressed (here, further compounded by whether voters use or not these public utilities) should be contained, but the decision on whether a larger portion of the budget should be allocated to their improvement should certainly take into account the views of the population.

Engaging people locally could be the first step to improve their involvement at a larger scale. This would allow electors a chance to see the palpable change their votes can have in their surrounding environment. Further to that, it contributes to their education as electors, giving them an opportunity to be called upon more often

\footnotetext{
${ }^{54}$ Tiago Sérgio Cabral, "A short guide to the legislative procedure in the European Union”, 179-180.

${ }_{55}$ Alessandra Silveira, Princípios de direito da União Europeia, 60-62.

${ }^{56}$ Alexis Vahlas, "The European Union as a new kind of federalism", in Federalismo em tempos de Renacionalização, 233.
} 
and to more directly be held accountable for their decisions. Evidence has also shown that positive experiences with e-participation and government responsiveness resulted in increased levels of trust in local government. ${ }^{57}$ There are chances for the EU to seize on this opportunity, either by creating funds in support of the enhancement of local e-participatory budgeting (attaching a clear obligation of promoting the source of those funds) or, in the long run, dedicating portions of its own funds and budget to this type of mechanism (an option that, we would presume, would require delicate political negotiation but is a position which could be reinforced if citizens were specially engaged in participatory budgeting initiatives).

From the considerations we gathered throughout the paper, it seems that, for the moment, focus should remain with strengthening existing mechanisms (such as, e-participatory budgeting and the ECI). Either way, any attempt to move towards a more digitised democracy should be preceded by initiatives to increase digital literacy and access to digital tools across the EU, as the Member States, at this stage, present rather heterogeneous realities in what concerns ability with and availability of digital tools.

In what regards the threats that were identified, particular attention should be given to information security. Thomas Rid and Ben Buchanan highlight the fact that the NSA leaks also showed us that the western democracies have better operational security than their Russian and Chinese counterparts ${ }^{58}$ and it seems that the issue was that they were looking the wrong way. Increased attention should be given to disinformation, misinformation and hacking campaigns, especially around electoral events. Now that malicious actors' capacity to impact democracy has been proven, the temptation to keep trying will be there.

Finally, concerning social media, we expect the debate on their regulation to intensify in the coming months, with the unfolding of the discussion surrounding the Digital Services and Digital Markets Acts. Regulation seems, more than ever, a necessity. For as much as social media has created spaces which allowed for autocracies to be taken down and fostered connections across the globe that would not be possible without them, it has also resulted in unprecedented threats to our democracy, our society, and our freedom. The irony is that their business model, by its own nature, thrives in a society littered with disinformation, as Dipayan Gosh notes: "there is an implicit alignment in the commercial goals of Facebook and the persuasive goals of the Russian disinformation operators. Both desire the user's maximal engagement with the content at hand (..) we cannot ignore the economic alignment of their objectives". ${ }^{59}$

Like with all other aspects of our lives, technology is starting to permeate democracy. It is paramount that the EU stays ahead of this evolution and manages to curate the most adequate mechanisms by which digital democracy will be a part of its future, adapting the latter's concepts to its own peculiarities, in the hopes that it might help to assuage the disenfranchisement that accelerated globalisation and digitalisation has brought about.

\footnotetext{
${ }^{57}$ Soonhee Kim and Jooho Lee, "e-Participation, transparency and trust in local government", Public Administration Review, v. 76, no. 6 (2012): 819-828, seen in Leonhard Hennen et al., European e-Democracy in practice, 96.

${ }^{58}$ Thomas Rid and Ben Buchanan, "Hacking democracy", 6.

${ }^{59}$ Dipayan Gosh, Terms of disservice, Introduction.
} 